\title{
インターナショナルスペシャルレクチャー2
}

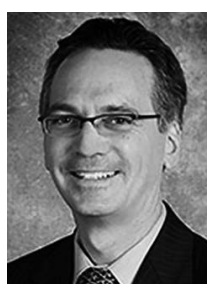

\section{Extending the Limits of Endoscopic Endonasal Surgery of the Skull Base}

\section{Carl H Snyderman}

Departments of Otolaryngology and Neurological Surgery, University of Pittsburgh School of Medicine; Otolaryngology Director, Center for Cranial Base Surgery, University of Pittsburgh Medical Center, Pittsburgh, Pennsylvania, USA

Endoscopic endonasal surgery (EES) of the skull base has evolved beyond the sella to include the entire ventral skull base. In the sagittal plane, surgical modules extend from the frontal sinus to the craniovertebral junction in a midline corridor. Access to the superior clivus is achieved with a pituitary transposition without loss of pituitary function. Coronal plane modules extend laterally to provide access to the anterior, middle and posterior cranial fossae. In the anterior coronal plane, a superomedial orbitotomy provides access to the anterior cranial base as far laterally as the mid-sagittal plane of the orbit. In the middle coronal plane, improved understanding of the compartments of the cavernous sinus allows full dissection of parasellar tumors. The transpterygoid approach provides access to the lateral recess of the sphenoid sinus and Meckel's cave. Suprapetrous approaches extend access further laterally across the floor of the middle cranial fossa. In the posterior coronal plane, transjugular tubercle and transcondylar approaches extend beyond the hypoglossal canal in an infrapetrous plane. Access to the petrous apex for chondromatous tumors is limited by the internal carotid artery (ICA). A new approach, the contralateral transmaxillary approach, allows complete dissection of the petrous apex deep to the petrous ICA as far as the internal auditory canal and jugular foramen. Inferiorly, tumors of the parapharyngeal space may be dissected to the parapharyngeal ICA.

The limitations of EES are determined by multiple factors. Anatomical limits include the major neural and vascular structures of the skull base. Other limits are imposed by patient, surgeon, and institutional factors. EES may be applied to all patient populations; the principles are the same for young pediatric patients despite the unique challenges of the pediatric population (decreased pneumatization of sinuses, smaller blood volume, etc.). Vascular tumors including aneurysms can be managed safely with EES. Oncological principles can be preserved with the management of sinonasal malignancy, often with superior outcomes. Improved methods of reconstruction allow reliable repair of large dural defects with acceptable morbidity. In particular, the employment of vascularized flaps (nasoseptal flap, extracranial pericranial flap, lateral nasal wall flap) in combination with selective use of lumbar spinal drainage, has dramatically lowered the risk of postoperative cerebrospinal fluid leak. EES is also limited by the training of surgeons. A systematic approach to training based on increasing levels of complexity and risk has been validated and is correlated with clinical outcomes. Surgical simulation allows teams to train for rare events such as vascular injury.

Further improvements in anatomical knowledge, surgical technology, and enhanced surgical training will further extend the limits of EES of the skull base.

\section{BIOGRAPHY}

Carl H. Snyderman, MD, MBA, is Professor of Otolaryngology and Neurological Surgery at the University of Pittsburgh School of Medicine and Otolaryngology Director of the Center for Cranial Base Surgery at the University of Pittsburgh Medical Center (UPMC). He is recognized internationally as a pioneer and leader in the development of the endoscopic endonasal approach, a minimally invasive surgical approach to the cranial base. He received his Medical Degree from the University of Chicago and completed his residency in otolaryngology and fellowship training in skull base surgery at the UPMC. Dr. Snyderman is co-editor of the book Skull Base Surgery, part of the Master Techniques in Otolaryngology Head and Neck Surgery series published by Wolters Kluwer, and co-editor of Operative-Otolaryngology-Head and Neck Surgery, 3rd Edition. He has also published numerous peer-reviewed articles and presents frequently at local, national, and international scientific meetings and courses. 